\title{
Review Article \\ Bile Acids, FXR, and Metabolic Effects of Bariatric Surgery
}

\author{
Olivier F. Noel, ${ }^{1,2}$ Christopher D. Still, ${ }^{3}$ George Argyropoulos, ${ }^{3}$ \\ Michael Edwards, ${ }^{1}$ and Glenn S. Gerhard ${ }^{1}$ \\ ${ }^{1}$ Temple University School of Medicine, Philadelphia, PA 19140, USA \\ ${ }^{2}$ Penn State College of Medicine, Hershey, PA 17033, USA \\ ${ }^{3}$ Geisinger Clinic, Danville, PA 17822, USA \\ Correspondence should be addressed to Glenn S. Gerhard; gsgerhard@temple.edu
}

Received 29 October 2015; Accepted 31 January 2016

Academic Editor: Francesco Saverio Papadia

Copyright (C) 2016 Olivier F. Noel et al. This is an open access article distributed under the Creative Commons Attribution License, which permits unrestricted use, distribution, and reproduction in any medium, provided the original work is properly cited.

\begin{abstract}
Overweight and obesity represent major risk factors for diabetes and related metabolic diseases. Obesity is associated with a chronic and progressive inflammatory response leading to the development of insulin resistance and type 2 diabetes (T2D) mellitus, although the precise mechanism mediating this inflammatory process remains poorly understood. The most effective intervention for the treatment of obesity, bariatric surgery, leads to glucose normalization and remission of T2D. Recent work in both clinical studies and animal models supports bile acids (BAs) as key mediators of these effects. BAs are involved in lipid and glucose homeostasis primarily via the farnesoid X receptor (FXR) transcription factor. BAs are also involved in regulating genes involved in inflammation, obesity, and lipid metabolism. Here, we review the novel role of BAs in bariatric surgery and the intersection between BAs and immune, obesity, weight loss, and lipid metabolism genes.
\end{abstract}

\section{Introduction}

Patients with morbid or extreme obesity (BMI $>40 \mathrm{~kg} / \mathrm{m}^{2}$ ), who constitute over $6 \%$ of the US population, a segment that has increased by $70 \%$ from 2000 to 2010 [1], have a prevalence of T2D of over 30\% [2]. The prevalence of type 2 diabetes mellitus is increasing in parallel with the increase in obesity. Obesity is associated with a chronic and progressive inflammatory response that is involved in the development of insulin resistance [3-6]. Proinflammatory cytokines and other molecules that are produced by adipocytes, macrophages, and other infiltrating immune cells can disrupt normal insulin signaling and glucose transport inducing insulin resistance $[7,8]$. Several antidiabetic drugs may act in part through modulation of adipocyte cytokine production [9], although no drugs have been developed targeting specific adipose derived cytokines and the precise mechanism involved in initiating and mediating the inflammatory processes associated with the pathophysiology of insulin resistance and T2D remains poorly understood. This gap in knowledge is significant since conventional medical management for T2D is only partially effective in achieving acceptable glycemic control and is particularly challenging in obese patients with multiple comorbidities due to metabolic and other related physiological effects.

\section{Bariatric Surgery}

The lack of adequate medical therapies for obesity and T2D has led to the use of bariatric surgery, which is the most effective therapy to induce significant and durable weight loss in patients with extreme obesity (BMI $>40 \mathrm{~kg} / \mathrm{m}^{2}$ ) [10-14]. Several types of bariatric surgery, including the commonly performed Roux-en-Y gastric bypass (RYGB) and sleeve gastrectomy (SG) operations, also cause resolution of dysglycemia, insulin resistance, and T2D within hours to days of the procedure, well before weight loss has occurred [15]. This has led to the increasing use of bariatric surgery and to the notion that "bariatric surgery has been shown to be the most effective treatment for obesity and T2DM, both in large well-matched clinical studies and RCTs" [16]. For example, in a single-center, nonblinded, randomized, controlled trial of 60 patients (ages $30-60$ years) with a BMI $>35 \mathrm{~kg} / \mathrm{m}^{2}$ with 
at least a 5-year history of T2D and a hemoglobin Alc $>7 \%$, who were randomly assigned to receive conventional medical therapy or undergo RYGB, no patients in the medical therapy group had achieved remission of $\mathrm{T} 2 \mathrm{D}$, defined as a fasting blood glucose $<100 \mathrm{mg} / \mathrm{dL}$ and a HGB Alc $<6.5 \%$ without use of medications at 2 years, whereas $75 \%$ of the patients who underwent RYGB were in remission [17]. Perhaps even more striking is the observation that glucose normalization often occurs within hours to days after the surgery, well before any significant weight loss has occurred [11].

Although the metabolic effects of bariatric surgery have been observed for over 50 years [18] and have been confirmed by numerous subsequent studies in humans and animal models $[19,20]$, the molecular mechanisms underlying these effects are not yet well delineated. For example, initial hypotheses focused on caloric restriction as a mechanism underlying increased glycemic control. Caloric restriction occurs with all bariatric procedures, in which patients undergo essentially identical pre- and perioperative protocols, but not all induce an amelioration of T2D [21]. Indeed, caloric restriction occurs after many surgical procedures [20] but they tend to worsen glycemic control due to the stress response from the surgery [22]. Much attention has also been focused on incretins, particularly glucagon-like peptide-1 (GLP-1). Recent reports using elegant study designs have suggested "a significant role" for GLP-1 in resolution of T2D after RYGB [23, 24], although several reviews [18, 20, 21] attribute only some or none of the antidiabetic effects to GLP1 , consistent with mouse studies in which GLP-1 was not required for either T2D resolution or weight loss after RYGB $[25,26]$.

The other main classes of hypotheses [20] are based on alterations in the flow and anatomic routing of ingested nutrients [21]. The foregut hypothesis posits that bypass and exclusion from contact with ingested nutrients of the proximal small intestine (foregut), primarily the duodenum, changes the production of a mediator that produces direct anti-T2D effects. Indeed, procedures that cause malabsorption through intestinal bypass have dramatic effects on T2D. This is also supported by the endoluminal sleeve (ES) device, which is endoscopically inserted and prevents ingesta that leaves the stomach from contacting the small intestine for a length similar to that bypassed in RYGB procedures and also results in resolution of T2D [27]. The lower intestinal or hindgut hypothesis is based on the premise that inappropriate delivery of ingested nutrients and/or digestive juices to more distal regions of the small intestine induces a putative molecular mediator that ameliorates T2D. Bile acids have been implicated as key molecules in this hypothesis [18, 21]. Recent work in both clinical studies and animal models supports a key role for bile acids [28-30]. Systemic BA levels are elevated in patients following RYGB [31-34], suggesting an increase in BA signaling after RYGB [35]. However, most studies (reviewed in [21]), including our own [32], have measured levels months after the perioperative period. BAs can regulate cholesterol, triglyceride, and glucose homeostasis [36], making BA regulated pathways attractive molecular targets to various diseases such as T2D, atherosclerosis, obesity, and other diseases $[30,36]$.
An apparent confounder to this hypothesis is the SG, an operation that is increasingly being used instead of RYGB that is a partial gastrectomy in which the stomach becomes a vertical tube or sleeve. The SG also results in resolution of T2D, which seems to contradict the inappropriate delivery of nutrients and digestive components to the distal intestine hypothesis. However, gastric transit is substantially increased in SG, expediting delivery through the duodenum into the distal intestine [21]. Recently FXR has been shown to be required for the antidiabetic effect of SG in mice [28]. Further delineation of the molecular mechanisms underlying these beneficial effects could provide targets for the development of new nonsurgical treatments [16].

\section{Novel Roles for Bile Acids in Energy Metabolism}

Bile acids are synthesized from cholesterol in the liver [37]. Ingestion of food causes bile acid secretion from the gallbladder through the common bile duct to the duodenum in order to facilitate the absorption of lipids and lipid-soluble vitamins via formation of micelles. Upon reaching the ileum, bile acids are transported by specific transport proteins to the portal circulation for recycling back to the liver. The process is highly efficient with over $95 \%$ of bile acids resorbed and the remaining $5 \%$ proceeding to the colon and excreting through the stool. Enterohepatic recycling of the bile acid pool occurs about 6-12 times per days; thus the net flux of bile acids through primarily the portal, but also the systemic, circulation is substantial.

The two primary bile acids produced by the liver (Figure 1) in humans are cholic acid (CA) and chenodeoxycholic acid (CDCA). These primary bile acids can undergo conjugation with glycine or taurine prior to secretion in the bile to form glycocholic acid (GCA), taurocholic acid (TCA), glycochenodeoxycholic acid (GCDCA), and tauroglycochenodeoxycholic acid (TCDCA). In the intestine, they can undergo dehydroxylation by gut bacteria to produce deoxycholic acid (DCA) and lithocholic acid (LCA). Further chemical modifications can also occur resulting in other minor species. Bile acids can bind to the G-protein coupled TGR5 cellular receptor to mediate signaling [37]. Bile acids also function as a ligand for a specific nuclear transcription factor (Figure 2), the farnesoid X receptor (FXR), which forms a heterodimeric complex with retinoic $\mathrm{X}$ receptor- $\alpha$ $(\mathrm{RXR}-\alpha)$ that binds to an inverted repeat sequence in gene promoters [38].

Bile acids not only function in lipid absorption absorbed in the gut but appear to be part of a broader physiological response to ingested nutrients that also involves glucose metabolism [39]. This is consistent with the anabolic need to store fatty acids as triglycerides, which requires a glycerol-3phosphate backbone that is derived from glucose [40, 41]. Bile acids thus appear to be involved in the regulation of glucose metabolism through modulation of FXR-regulated pathways. $\mathrm{FXR}^{-/-}$mice exhibit peripheral insulin resistance, reduced glucose disposal, and decreased adipose tissue and skeletal muscle insulin signaling, and, conversely, activation of FXR 

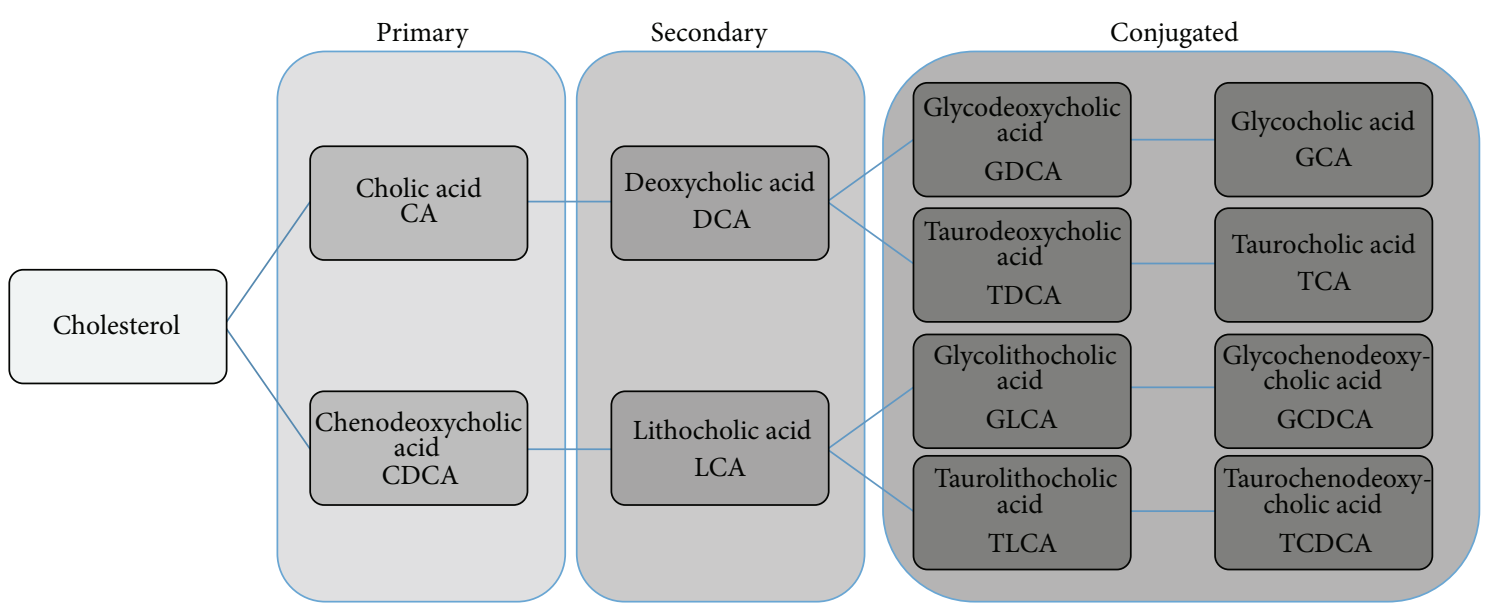

FIgURE 1: Major bile acids. The primary bile acids are synthesized from cholesterol in the liver. Secondary bile acids are formed by dehydroxylation of primary bile acids by intestinal bacteria. Primary and secondary bile acids can also undergo conjugation with taurine or glycine in the liver.

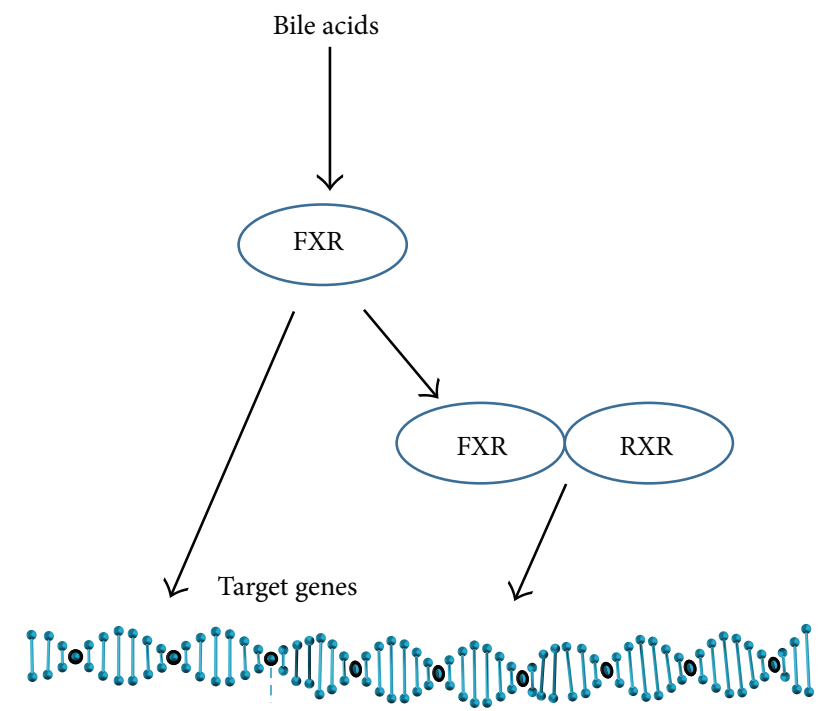

Figure 2: Mechanism of bile acid gene regulation. Bile acids can bind to the farnesoid $\mathrm{X}$ receptor (FXR) transcription factor which can regulate gene expression through binding to specific DNA motifs and can heterodimerize with retinoic X receptor- $\alpha$ (RXR- $\alpha)$ to regulate the expression of target genes.

by the agonist GW4064 in insulin-resistant ob/ob mice reduced hyperinsulinemia and improved glucose tolerance [42].

\section{Metabolism and the Complement Alternative Pathway}

One of the inflammatory pathways dysregulated in obesity with a connection to bile acid metabolism is the complement system, a complex network of soluble proteins and membrane receptors largely known for their roles in immunity. The system can be activated to provide immune defense through a stepwise series of proteolytic steps to produce cytolytic complexes. However, there are "sublytic" roles for the complement system in energy metabolism [43]. Activation of complement to fight infections is an energy intensive process; thus dual roles in energy maintenance may have evolved as part of coordinate regulation of immunity and metabolism to manage energy needs [44]. Complement component 3 (C3) is a key complement molecule because it exists in the blood at relatively high concentrations in a nonreactive native form but can be mobilized by three primary activation pathways, the classical, alternate, and lectin, to generate multiple downstream molecules and complexes $[45,46]$. Several C3 derived products, including $\mathrm{C} 3 \mathrm{a}$ and its corresponding desArg form, are not required for the generation of membrane attack complexes that lyse bacteria.

A potential metabolic role for C3 was first suggested by the finding of low complement levels in lipodystrophy [47]. Adipocytes are known to produce and secrete C3, as well as the alternative pathway activation components Factor B and Factor D, also known as adipsin [48]. Serum levels of C3 thus increase with increasing fat mass and decrease with weight loss [49] and have been implicated in T2D [50]. In the alternative activation pathway, C3 converts spontaneously in plasma to activated $\mathrm{C} 3 * \mathrm{H} 2 \mathrm{O}$ which combines with Factor $\mathrm{B}$ to form $\mathrm{C} 3 * \mathrm{H} 2 \mathrm{OB}$ [51]. Adipsin then cleaves bound Factor B to generate $\mathrm{C} 3 * \mathrm{H} 2 \mathrm{OBb}$. $\mathrm{C} 3 * \mathrm{H} 2 \mathrm{OBb}$ is an active convertase that cleaves $\mathrm{C} 3$ to generate $\mathrm{C} 3 \mathrm{a}$. C3a can undergo cleavage of the $\mathrm{N}$-terminal arginine by plasma carboxypeptidase $\mathrm{B}(\mathrm{CpB})$ to produce C3adesArg, also known as Acylation Stimulating Protein (ASP). ASP binds to C5a like-2 receptor (C5L2 or GPR77) with high affinity [52] and has been shown to stimulate triglyceride synthesis and glucose transport in vitro [41, $53,54]$. C5L $2^{-/-}$mice have higher glucose and insulin plasma levels, with increased expression of insulin resistance genes in adipose tissue [55] and are highly insulin resistant upon glucose tolerance testing [56]. Consistent with the C5L2 knockout mouse findings, administration of ASP to diet-induced obese mice significantly improved glucose tolerance [40]. 


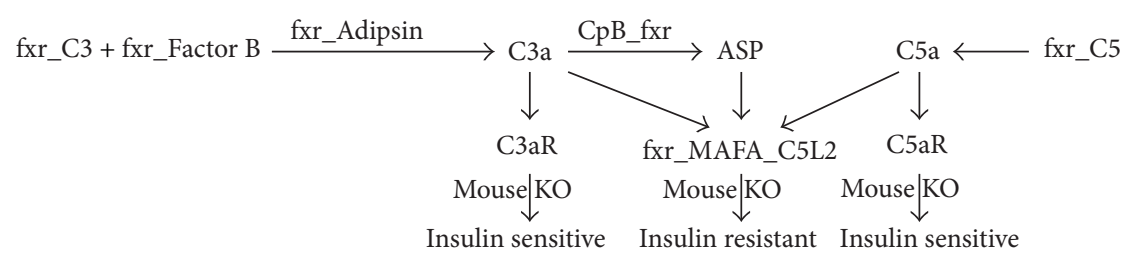

FIGURE 3: Complement alternative activation pathway with corresponding receptors and mouse knockout phenotypes.

TABLE 1: Location of FXR and MAFA consensus binding sequences within $1000 \mathrm{bp}$ of complement alternative activation pathway genes. $\mathrm{C} 3 \mathrm{aR}$ and $\mathrm{C5} \mathrm{aR}$ genes lack either motif.

\begin{tabular}{lccc}
\hline Gene & Motif & Position & Location \\
\hline C3 & FXR & -154 & Upstream \\
C5 & FXR & -454 & Upstream \\
Factor B & FXR & -172 & Upstream \\
Adipsin & FXR & -417 & Upstream \\
CpB & FXR & 537 & Downstream \\
C5L2 & FXR & -81 & Upstream \\
C5L2 & MAFA & -102 & Upstream \\
C3aR & None & - & - \\
C5aR & None & - & - \\
\hline
\end{tabular}

\section{FXR and the Complement Alternative Pathway}

The regulation of $\mathrm{C} 3$ by bile acids via FXR binding motifs has been extensively characterized [57]. We therefore searched the genes that constitute the entire C3-ASP conversion pathway for FXR motifs using MotifMap [58, 59]. The C3, Factor B, Adipsin, CpB, and C5L2 genes all possess predicted FXR binding sites (Table 1). We also observed that the C5L2 promoter contained a V-maf musculoaponeurotic fibrosarcoma oncogene homologue A (MAFA) motif, which plays a key role in the tightly regulated mechanism of induction of insulin gene transcription by glucose [60], suggesting that C5L2 is also regulated by glucose. Further evidence implicating this pathway in glucose metabolism is the observation that adipsin $^{-/-}$knockout mice exhibit worsened glucose metabolism in diet-induced obesity [61] that recently has been shown to be associated with a role in insulin secretion by pancreatic $\beta$ cells [62].

These data support a pathway (Figure 3) in which we hypothesize that the C3 alternative activation pathway is regulated by bile acids to produce ASP that binds to C5L2 to modulate glucose metabolism, consistent with knockout of the C5L2 gene that renders mice insulin resistant.

\section{FXR and Weight Loss and Obesity Genes}

A variety of genetic factors have been identified that associate with weight loss after bariatric surgery including those found through Genome-Wide Association Studies (GWAS) [63-67]. In addition, a recent obesity GWAS of 339,224 individuals identified 97 BMI-associated loci [68] and a

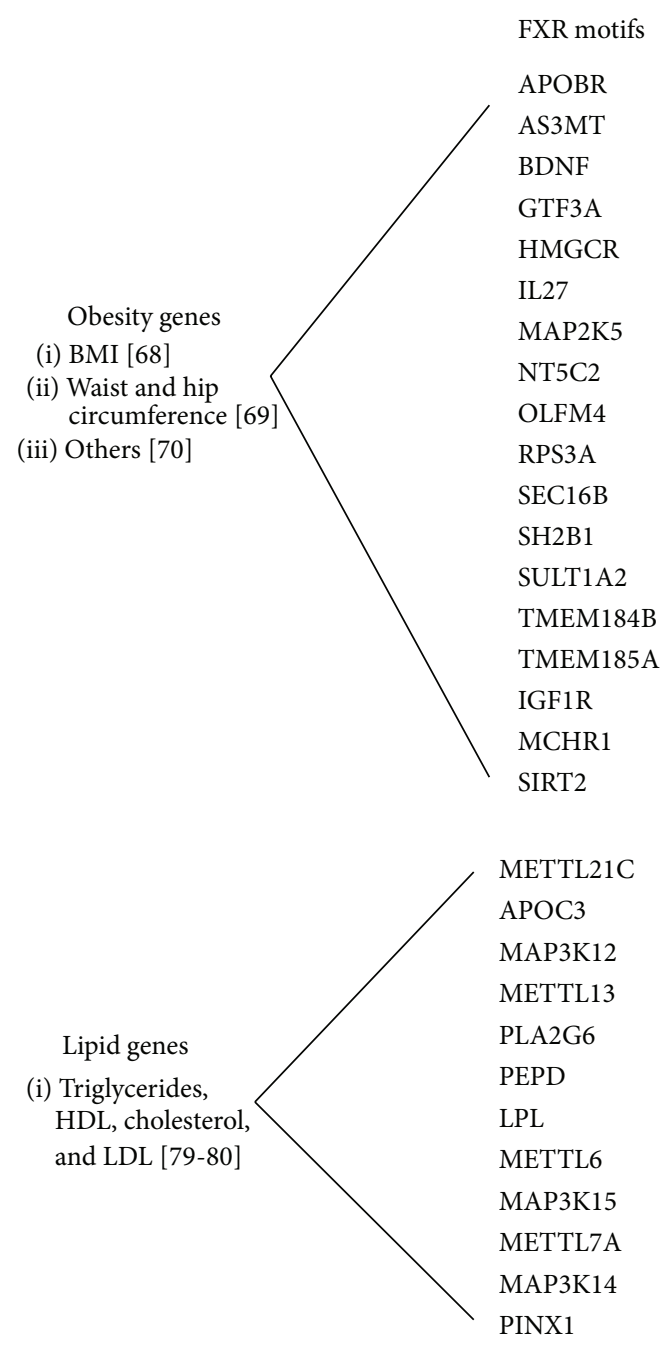

FIGURE 4: Subset of obesity and lipid associated genes that possess in silico identified FXR motifs.

GWAS of waist and hip circumference and related traits of 224,459 individuals identified an additional 19 loci new loci [69]. A number of genes have also been associated with Mendelian forms of obesity [70]. We searched all of these genes for FXR motifs using the MotifMap algorithm [58, 71] to identify the following set: APOBR, AS3MT, BDNF, GTF3A, HMGCR, IL27, MAP2K5, NT5C2, OLFM4, RPS3A, SEC16B, SH2B1, SULT1A2, TMEM184B, TMEM185A, IGF1R, MCHR1, and SIRT2 (Figure 4). We then searched PubMed and found evidence of regulation by bile acids for HMGCR [72] and BDNF [73]. We also searched the literature for 
evidence for whether these genes were expressed in PBMCs and found data for MCHR1 [74], as well as SIRT2 [75] in which expression in PBMCs was modulated caloric restriction [76], and BDNF in which differences in the epigenetic methylation of BDNF were detected in PBMCs in patients who lost weight in a dietary/behavioral weight loss regimen [77]. Decreased levels of BDNF through mutation are associated with obese phenotypes and hyperphagia; thus increasing levels may favor weight loss [78]. Decreasing SIRT2 has been shown to increase $\beta$-oxidation in adipocytes [75].

\section{FXR-Regulated Lipid Genes}

Triglyceride (TRIG) levels decline and high density lipoprotein cholesterol (HDL-C) levels increase in a majority of patients in the first year following surgery, with a substantial correlation between the degrees of change. We conducted a similar in silico search for FXR motifs in a recent compilation of TRIG GWAS genes [79], as well as our own lipid GWAS loci [80], to identify METTL21C, APOC3, MAP3K12, METTL13, PLA2G6, PEPD, LPL, METTL6, MAP3K15, METTL7A, MAP3K14, and PINX1 (Figure 4). Evidence of regulation by bile acids exists for LPL [81]. Interestingly, out of 72 genes, LPL is one of only 10 that were found to be associated with both TRIG and HDL by GWAS. Given the correlation in improvement in TRIG and HDL that we have found following bariatric surgery, LPL is a leading candidate as an FXR-mediated mechanism underlying the improvement in metabolic syndrome related dyslipidemia characterized by high TRIG and low HDL [82].

\section{Summary}

Bariatric surgery has complex effects [20], and thus multiple molecular mechanisms are likely involved. Bile acid signaling through FXR may be common mechanism involved in these effects, though operating through distinct pathways.

\section{Conflict of Interests}

The authors declare that they have no competing interests.

\section{Authors' Contribution}

Olivier F. Noel performed the genetic analysis and helped in drafting the paper. Christopher D. Still, George Argyropoulos, and Michael Edwards participated in the design of the study and helped in drafting the paper. Glenn S. Gerhard conceived and designed the study and prepared the paper. All the authors read and approved the final paper.

\section{Acknowledgment}

This work was supported by R01 DK088231 from the National Institutes of Health.

\section{References}

[1] R. Sturm and A. Hattori, "Morbid obesity rates continue to rise rapidly in the United States," International Journal of Obesity, vol. 37, no. 6, pp. 889-891, 2013.

[2] D. Hofsø, T. Jenssen, H. Hager, J. Røislien, and J. Hjelmesæth, "Fasting plasma glucose in the screening for type 2 diabetes in morbidly obese subjects," Obesity Surgery, vol. 20, no. 3, pp. 302$307,2010$.

[3] J. Chmelar, K.-J. Chung, and T. Chavakis, "The role of innate immune cells in obese adipose tissue inflammation and development of insulin resistance," Thrombosis and Haemostasis, vol. 109, no. 3, pp. 399-406, 2013.

[4] A. W. Ferrante Jr., "Obesity-induced inflammation: a metabolic dialogue in the language of inflammation," Journal of Internal Medicine, vol. 262, no. 4, pp. 408-414, 2007.

[5] S. Schenk, M. Saberi, and J. M. Olefsky, "Insulin sensitivity: modulation by nutrients and inflammation," The Journal of Clinical Investigation, vol. 118, no. 9, pp. 2992-3002, 2008.

[6] S. P. Weisberg, D. McCann, M. Desai, M. Rosenbaum, R. L. Leibel, and A. W. Ferrante Jr., "Obesity is associated with macrophage accumulation in adipose tissue," The Journal of Clinical Investigation, vol. 112, no. 12, pp. 1796-1808, 2003.

[7] C. N. Lumeng, S. M. Deyoung, and A. R. Saltiel, "Macrophages block insulin action in adipocytes by altering expression of signaling and glucose transport proteins," American Journal of Physiology-Endocrinology and Metabolism, vol. 292, no. 1, pp. E166-E174, 2007.

[8] H. Xu, G. T. Barnes, Q. Yang et al., "Chronic inflammation in fat plays a crucial role in the development of obesity-related insulin resistance," The Journal of Clinical Investigation, vol. 112, no. 12, pp. 1821-1830, 2003.

[9] J. Westerink and F. L. J. Visseren, "Pharmacological and nonpharmacological interventions to influence adipose tissue function," Cardiovascular Diabetology, vol. 10, article 13, 2011.

[10] K. L. Butner, S. M. Nickols-Richardson, S. F. Clark, W. K. Ramp, and W. G. Herbert, "A review of weight loss following Rouxen-Y gastric bypass vs restrictive bariatric surgery: impact on adiponectin and insulin," Obesity Surgery, vol. 20, no. 5, pp. 559$568,2010$.

[11] H. Buchwald, R. Estok, K. Fahrbach et al., "Weight and type 2 diabetes after bariatric surgery: systematic review and metaanalysis," The American Journal of Medicine, vol. 122, no. 3, pp. 248.e5-256.e5, 2009.

[12] J. B. Dixon, D. K. Murphy, J. E. Segel, and E. A. Finkelstein, "Impact of laparoscopic adjustable gastric banding on type 2 diabetes," Obesity Reviews, vol. 13, no. 1, pp. 57-67, 2012.

[13] C. V. Ferchak and L. F. Meneghini, "Obesity, bariatric surgery and type 2 diabetes-a systematic review," Diabetes/Metabolism Research and Reviews, vol. 20, no. 6, pp. 438-445, 2004.

[14] H. M. Heneghan, S. Nissen, and P. R. Schauer, "Gastrointestinal surgery for obesity and diabetes: weight loss and control of hyperglycemia," Current Atherosclerosis Reports, vol. 14, no. 6, pp. 579-587, 2012.

[15] J. P. Thaler and D. E. Cummings, "Minireview: hormonal and metabolic mechanisms of diabetes remission after gastrointestinal surgery," Endocrinology, vol. 150, no. 6, pp. 2518-2525, 2009.

[16] A. D. Miras and C. W. le Roux, "Can medical therapy mimic the clinical efficacy or physiological effects of bariatric surgery?" International Journal of Obesity, vol. 38, no. 3, pp. 325-333, 2014. 
[17] G. Mingrone, S. Panunzi, A. De Gaetano et al., "Bariatric surgery versus conventional medical therapy for type 2 diabetes," The New England Journal of Medicine, vol. 366, no. 17, pp. 1577-1585, 2012.

[18] R. E. Allen, T. D. Hughes, J. L. Ng et al., "Mechanisms behind the immediate effects of Roux-en-Y gastric bypass surgery on type 2 diabetes," Theoretical Biology and Medical Modelling, vol. 10, no. 1, article 45, 2013.

[19] H. Ashrafian, M. Bueter, K. Ahmed et al., "Metabolic surgery: an evolution through bariatric animal models," Obesity Reviews, vol. 11, no. 12, pp. 907-920, 2010.

[20] K. T. Nguyen and J. Korner, "The sum of many parts: potential mechanisms for improvement in glucose homeostasis after bariatric surgery," Current Diabetes Reports, vol. 14, article 481, 2014.

[21] S. Madsbad, C. Dirksen, and J. J. Holst, "Mechanisms of changes in glucose metabolism and bodyweight after bariatric surgery," The Lancet Diabetes and Endocrinology, vol. 2, no. 2, pp. 152-164, 2014.

[22] F. A. McAlister, J. Man, L. Bistritz, H. Amad, and P. Tandon, "Diabetes and coronary artery bypass surgery: an examination of perioperative glycemic control and outcomes," Diabetes Care, vol. 26, no. 5, pp. 1518-1524, 2003.

[23] G. Fruhbeck and R. Nogueiras, "GLP-1: the oracle for gastric bypass?” Diabetes, vol. 63, no. 2, pp. 399-401, 2014.

[24] J. Schirra and B. Göke, "GLP-1-a candidate humoral mediator for glucose control after Roux-en-Y gastric bypass," Diabetes, vol. 63, no. 2, pp. 387-389, 2014.

[25] M. Mokadem, J. F. Zechner, R. F. Margolskee, D. J. Drucker, and V. Aguirre, "Effects of Roux-en-Y gastric bypass on energy and glucose homeostasis are preserved in two mouse models of functional glucagon-like peptide-1 deficiency," Molecular Metabolism, vol. 3, no. 2, pp. 191-201, 2014.

[26] J. Ye, Z. Hao, M. B. Mumphrey et al., "GLP-1 receptor signaling is not required for reduced body weight after RYGB in rodents," The American Journal of Physiology-Regulatory Integrative and Comparative Physiology, vol. 306, no. 5, pp. R352-R362, 2014.

[27] B. J. Sandler, R. Rumbaut, C. P. Swain et al., "Human experience with an endoluminal, endoscopic, gastrojejunal bypass sleeve," Surgical Endoscopy, vol. 25, no. 9, pp. 3028-3033, 2011.

[28] K. K. Ryan, V. Tremaroli, C. Clemmensen et al., "FXR is a molecular target for the effects of vertical sleeve gastrectomy," Nature, vol. 509, no. 7499, pp. 183-188, 2014.

[29] P. O. Ganrot, K. Gydell, and H. Ekelund, "Serum concentration of alpha-2-macroglobulin, haptoglobin and alpha-1-antitrypsin in diabetes mellitus," Acta Endocrinologica, vol. 55, no. 3, pp. 537-544, 1967.

[30] F. G. Schaap, M. Trauner, and P. L. M. Jansen, "Bile acid receptors as targets for drug development," Nature Reviews Gastroenterology and Hepatology, vol. 11, no. 1, pp. 55-67, 2014.

[31] R. Kohli, D. Bradley, K. D. Setchell, J. C. Eagon, N. Abumrad, and S. Klein, "Weight loss induced by Roux-en-Y gastric bypass but not laparoscopic adjustable gastric banding increases circulating bile acids," Journal of Clinical Endocrinology and Metabolism, vol. 98, no. 4, pp. E708-E712, 2013.

[32] G. S. Gerhard, A. M. Styer, G. C. Wood et al., "A role for fibroblast growth factor 19 and bile acids in diabetes remission after Roux-en-Y gastric bypass," Diabetes Care, vol. 36, no. 7, pp. 1859-1864, 2013.

[33] A. Myronovych, M. Kirby, K. K. Ryan et al., "Vertical sleeve gastrectomy reduces hepatic steatosis while increasing serum bile acids in a weight-loss-independent manner," Obesity, vol. 22, no. 2, pp. 390-400, 2014.

[34] M.-E. Patti, S. M. Houten, A. C. Bianco et al., "Serum bile acids are higher in humans with prior gastric bypass: potential contribution to improved glucose and lipid metabolism," Obesity, vol. 17, no. 9, pp. 1671-1677, 2009.

[35] P. L. M. Jansen, J. van Werven, E. Aarts et al., "Alterations of hormonally active fibroblast growth factors after Roux-en-Y gastric bypass surgery," Digestive Diseases, vol. 29, no. 1, pp. 4851, 2011.

[36] S. M. Houten, M. Watanabe, and J. Auwerx, "Endocrine functions of bile acids," The EMBO Journal, vol. 25, no. 7, pp. 14191425, 2006.

[37] J. Prawitt, S. Caron, and B. Staels, "Bile acid metabolism and the pathogenesis of type 2 diabetes," Current Diabetes Reports, vol. 11, no. 3, pp. 160-166, 2011.

[38] M. O. Hoeke, J. Heegsma, M. Hoekstra, H. Moshage, and K. N. Faber, "Human FXR regulates SHP expression through direct binding to an LRH-1 binding site, independent of an IR-1 and LRH-1," PLoS ONE, vol. 9, no. 2, Article ID e88011, 2014.

[39] F. Kuipers, V. W. Bloks, and A. K. Groen, "Beyond intestinal soap-bile acids in metabolic control," Nature Reviews Endocrinology, vol. 10, no. 8, pp. 488-498, 2014.

[40] A. Fisette, P. Poursharifi, K. Oikonomopoulou, M. N. Munkonda, M. Lapointe, and K. Cianflone, "Paradoxical glucose-sensitizing yet proinflammatory effects of acute ASP administration in mice," Mediators of Inflammation, vol. 2013, Article ID 713284, 9 pages, 2013.

[41] R. Germinario, A. D. Sniderman, S. Manuel, S. P. Lefebvre, A. Baldo, and K. Cianflone, "Coordinate regulation of triacylglycerol synthesis and glucose transport by acylation-stimulating protein," Metabolism, vol. 42, no. 5, pp. 574-580, 1993.

[42] B. Cariou, K. van Harmelen, D. Duran-Sandoval et al., "The farnesoid $\mathrm{X}$ receptor modulates adiposity and peripheral insulin sensitivity in mice," The Journal of Biological Chemistry, vol. 281, no. 16, pp. 11039-11049, 2006.

[43] E. Hertle, M. M. J. van Greevenbroek, and C. D. A. Stehouwer, "Complement C3: an emerging risk factor in cardiometabolic disease," Diabetologia, vol. 55, no. 4, pp. 881-884, 2012.

[44] G. S. Hotamisligil, "Inflammation and metabolic disorders," Nature, vol. 444, no. 7121, pp. 860-867, 2006.

[45] O. A. Hamad, J. Bäck, P. H. Nilsson, B. Nilsson, and K. N. Ekdahl, "Platelets, complement, and contact activation: partners in inflammation and thrombosis," Advances in Experimental Medicine and Biology, vol. 946, pp. 185-205, 2012.

[46] D. Ricklin, G. Hajishengallis, K. Yang, and J. D. Lambris, "Complement: a key system for immune surveillance and homeostasis," Nature Immunology, vol. 11, no. 9, pp. 785-797, 2010.

[47] J. G. P. Sissons, R. J. West, J. Fallows et al., "The complement abnormalities of lipodystrophy," The New England Journal of Medicine, vol. 294, no. 9, pp. 461-465, 1976.

[48] M. Pattrick, J. Luckett, L. Yue, and C. Stover, "Dual role of complement in adipose tissue," Molecular Immunology, vol. 46, no. 5, pp. 755-760, 2009.

[49] A. Hernández-Mijares, C. Bañuls, L. Bellod et al., "Effect of weight loss on C3 and C4 components of complement in obese patients," European Journal of Clinical Investigation, vol. 42, no. 5, pp. 503-509, 2012. 
[50] A. Onat, G. Can, R. Rezvani, and K. Cianflone, "Complement C3 and cleavage products in cardiometabolic risk," Clinica Chimica Acta, vol. 412, no. 13-14, pp. 1171-1179, 2011.

[51] T. Fujita, "Extra-immunological role of complement activation in diabetic nephropathy," OA Nephrology, vol. 1, no. 2, article 19, 2013.

[52] D. Kalant, S. A. Cain, M. Maslowska, A. D. Sniderman, K. Cianflone, and P. N. Monk, "The chemoattractant receptor-like protein C5L2 binds the C3a des-Arg77/acylation-stimulating protein," The Journal of Biological Chemistry, vol. 278, pp. 1112311129, 2003.

[53] M. Maslowska, A. D. Sniderman, R. Germinario, and K. Cianflone, "ASP stimulates glucose transport in cultured human adipocytes," International Journal of Obesity, vol. 21, no. 4, pp. 261-266, 1997.

[54] Y. Tao, K. Cianflone, A. D. Sniderman, S. P. Colby-Germinario, and R. J. Germinario, "Acylation-stimulating protein (ASP) regulates glucose transport in the rat L6 muscle cell line," Biochimica et Biophysica Acta, vol. 1344, no. 3, pp. 221-229, 1997.

[55] D. Gauvreau, A. Gupta, A. Fisette, F.-Q. Tom, and K. Cianflone, "Deficiency of C5L2 increases macrophage infiltration and alters adipose tissue function in mice," PLOS ONE, vol. 8, no. 4, Article ID e60795, 2013.

[56] A. Fisette, M. N. Munkonda, K. Oikonomopoulou, S. Paglialunga, J. D. Lambris, and K. Cianflone, "C5L2 receptor disruption enhances the development of diet-induced insulin resistance in mice," Immunobiology, vol. 218, no. 1, pp. 127-133, 2013.

[57] J. Li, P. C. Pircher, I. G. Schulman, and S. K. Westin, "Regulation of complement C3 expression by the bile acid receptor FXR," The Journal of Biological Chemistry, vol. 280, no. 9, pp. 74277434, 2005.

[58] K. Daily, V. R. Patel, P. Rigor, X. Xie, and P. Baldi, "MotifMap: integrative genome-wide maps of regulatory motif sites for model species," BMC Bioinformatics, vol. 12, article 495, 2011.

[59] G. Xie, Z. Peng, and J.-P. Raufman, "Src-mediated aryl hydrocarbon and epidermal growth factor receptor cross talk stimulates colon cancer cell proliferation," The American Journal of Physiology_Gastrointestinal and Liver Physiology, vol. 302, no. 9, pp. G1006-G1015, 2012.

[60] S. S. Andrali, M. L. Smapley, N. L. Vanderford, and S. Özcan, "Glucose regulation of insulin gene expression in pancreatic $\beta$ cells," Biochemical Journal, vol. 415, no. 1, pp. 1-10, 2008.

[61] Y. Xu, M. Ma, G. C. Ippolito, H. W. Schroeder Jr., M. C. Carroll, and J. E. Volanakis, "Complement activation in factor Ddeficient mice," Proceedings of the National Academy of Sciences of the United States of America, vol. 98, no. 25, pp. 14577-14582, 2001.

[62] J. C. Lo, S. Ljubicic, B. Leibiger et al., "Adipsin is an adipokine that improves $\beta$ cell function in diabetes," Cell, vol. 158, no. 1, pp. 41-53, 2014.

[63] C. D. Still, G. C. Wood, X. Chu et al., "High allelic burden of four obesity SNPs is associated with poorer weight loss outcomes following gastric bypass surgery," Obesity, vol. 19, no. 8, pp. 1676-1683, 2011.

[64] B. S. Moore, U. L. Mirshahi, E. A. Yost et al., "Long-term weightloss in gastric bypass patients carrying melanocortin 4 receptor variants," PLoS ONE, vol. 9, no. 4, Article ID e93629, 2014.

[65] U. L. Mirshahi, C. D. Still, K. K. Masker, G. S. Gerhard, D. J. Carey, and T. Mirshahi, "The $\operatorname{MC} 4 R(I 251 L)$ allele is associated with better metabolic status and more weight loss after gastric bypass surgery," Journal of Clinical Endocrinology and Metabolism, vol. 96, no. 12, pp. E2088-E2096, 2011.

[66] E. S. Rinella, C. Still, Y. Shao et al., "Genome-wide association of single-nucleotide polymorphisms with weight loss outcomes after Roux-en-Y gastric bypass surgery," The Journal of Clinical Endocrinology \& Metabolism, vol. 98, no. 6, pp. E1131-E1136, 2013.

[67] I. J. Hatoum, D. M. Greenawalt, C. Cotsapas, M. J. Daly, M. L. Reitman, and L. M. Kaplan, "Weight loss after gastric bypass is associated with a variant at 15q26.1," The American Journal of Human Genetics, vol. 92, no. 5, pp. 827-834, 2013.

[68] A. E. Locke, B. Kahali, S. I. Berndt et al., "Genetic studies of body mass index yield new insights for obesity biology," Nature, vol. 518, no. 7538, pp. 197-206, 2015.

[69] D. Shungin, T. W. Winkler, D. C. Croteau-Chonka et al., "New genetic loci link adipose and insulin biology to body fat distribution," Nature, vol. 518, no. 7538, pp. 187-196, 2015.

[70] A. A. van der Klaauw and I. S. Farooqi, “The hunger genes: pathways to obesity," Cell, vol. 161, no. 1, pp. 119-132, 2015.

[71] X. Xie, P. Rigor, and P. Baldi, "MotifMap: a human genome-wide map of candidate regulatory motif sites," Bioinformatics, vol. 25, no. 2, pp. 167-174, 2009.

[72] P. F. Duckworth, Z. Reno Vlahcevic, E. J. Studer et al., "Effect of hydrophobie bile acids on 3-hydroxy-3-methylglutarylcoenzyme A reductase activity and mRNA levels in the rat," The Journal of Biological Chemistry, vol. 266, no. 15, pp. 9413-9418, 1991.

[73] G. Vivacqua, A. Renzi, G. Carpino, A. Franchitto, and E. Gaudio, "Expression of brain derivated neurotrophic factor and of its receptors: TrKB and p75NT in normal and bile duct ligated rat liver," Italian Journal of Anatomy and Embryology, vol. 119, no. 2, pp. 111-129, 2014.

[74] M. Verlaet, A. Adamantidis, B. Coumans et al., "Human immune cells express ppMCH mRNA and functional MCHR1 receptor," FEBS Letters, vol. 527, no. 1-3, pp. 205-210, 2002.

[75] J. Krishnan, C. Danzer, T. Simka et al., "Dietary obesityassociated Hiflalpha activation in adipocytes restricts fatty acid oxidation and energy expenditure via suppression of the Sirt2NAD+ system," Genes \& Development, vol. 26, pp. 259-270, 2012.

[76] A. B. Crujeiras, D. Parra, E. Goyenechea, and J. A. Martinez, "Sirtuin gene expression in human mononuclear cells is modulated by caloric restriction," European Journal of Clinical Investigation, vol. 38, no. 9, pp. 672-678, 2008.

[77] Y.-T. Huang, J. Z. J. Maccani, N. L. Hawley, R. R. Wing, K. T. Kelsey, and J. M. McCaffery, "Epigenetic patterns in successful weight loss maintainers: a pilot study," International Journal of Obesity, vol. 39, pp. 865-868, 2015.

[78] H. Rosas-Vargas, J. D. Martínez-Ezquerro, and T. Bienvenu, "Brain-derived neurotrophic factor, food intake regulation, and obesity," Archives of Medical Research, vol. 42, no. 6, pp. 482494, 2011.

[79] L. A. Lange, C. J. Willer, and S. S. Rich, "Recent developments in genome and exome-wide analyses of plasma lipids," Current Opinion in Lipidology, vol. 26, no. 2, pp. 96-102, 2015.

[80] A. Parihar, G. C. Wood, X. Chu et al., "Extension of GWAS results for lipid-related phenotypes to extreme obesity using Electronic Health Record (EHR) data and the Metabochip," Frontiers in Genetics, vol. 5, article 222, 2014. 
[81] G. Xu, L.-X. Pan, H. Li et al., "Dietary cholesterol stimulates CYP7A1 in rats because farnesoid X receptor is not activated," The American Journal of Physiology-Gastrointestinal and Liver Physiology, vol. 286, no. 5, pp. G730-G735, 2004.

[82] S. Lim and R. H. Eckel, "Pharmacological treatment and therapeutic perspectives of metabolic syndrome," Reviews in Endocrine and Metabolic Disorders, vol. 15, no. 4, pp. 329-341, 2014. 


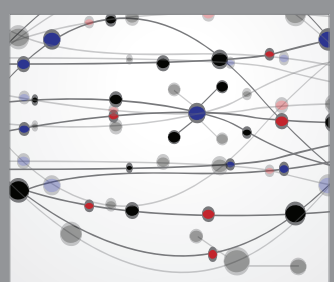

The Scientific World Journal
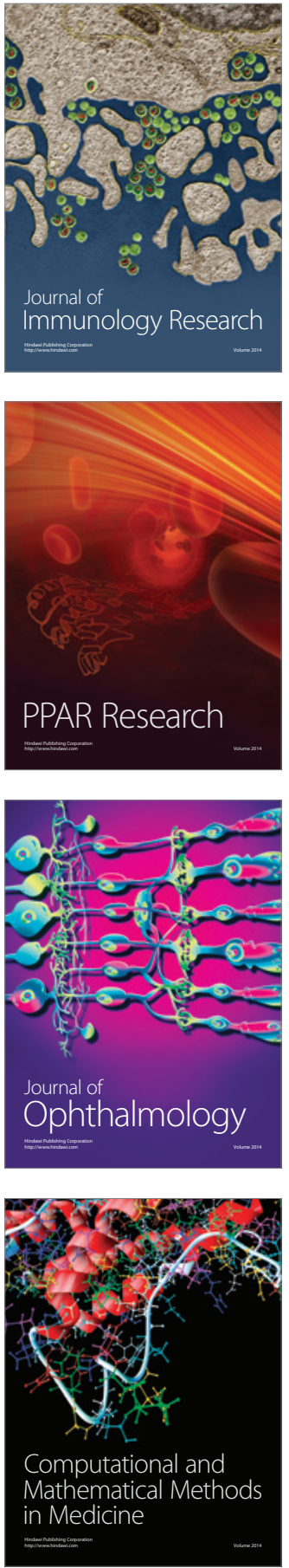

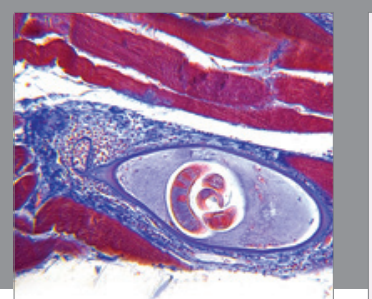

Gastroenterology Research and Practice

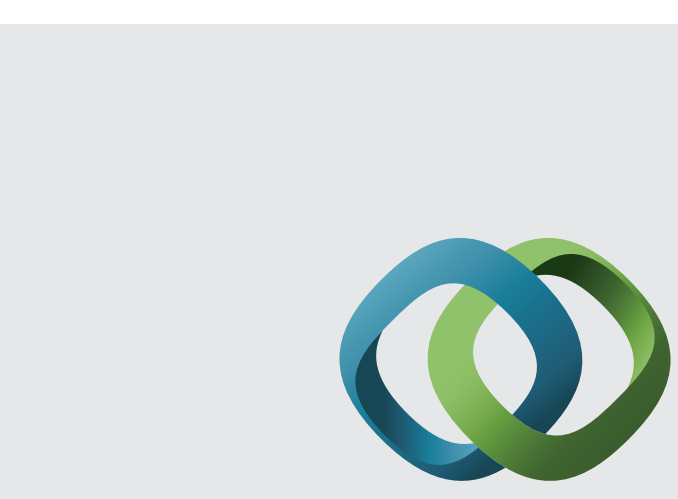

\section{Hindawi}

Submit your manuscripts at

http://www.hindawi.com
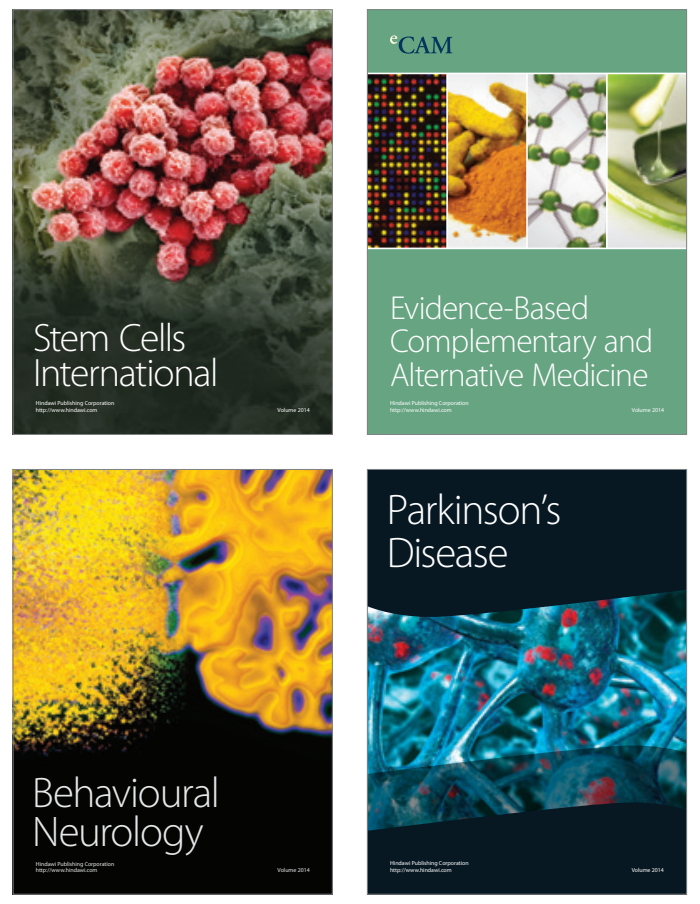
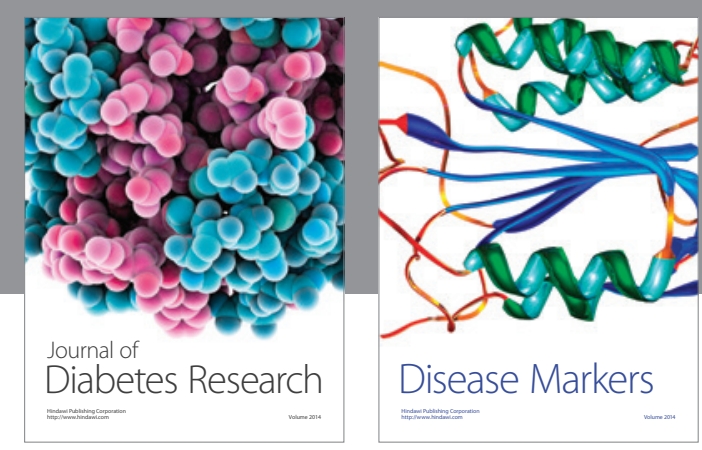

Disease Markers
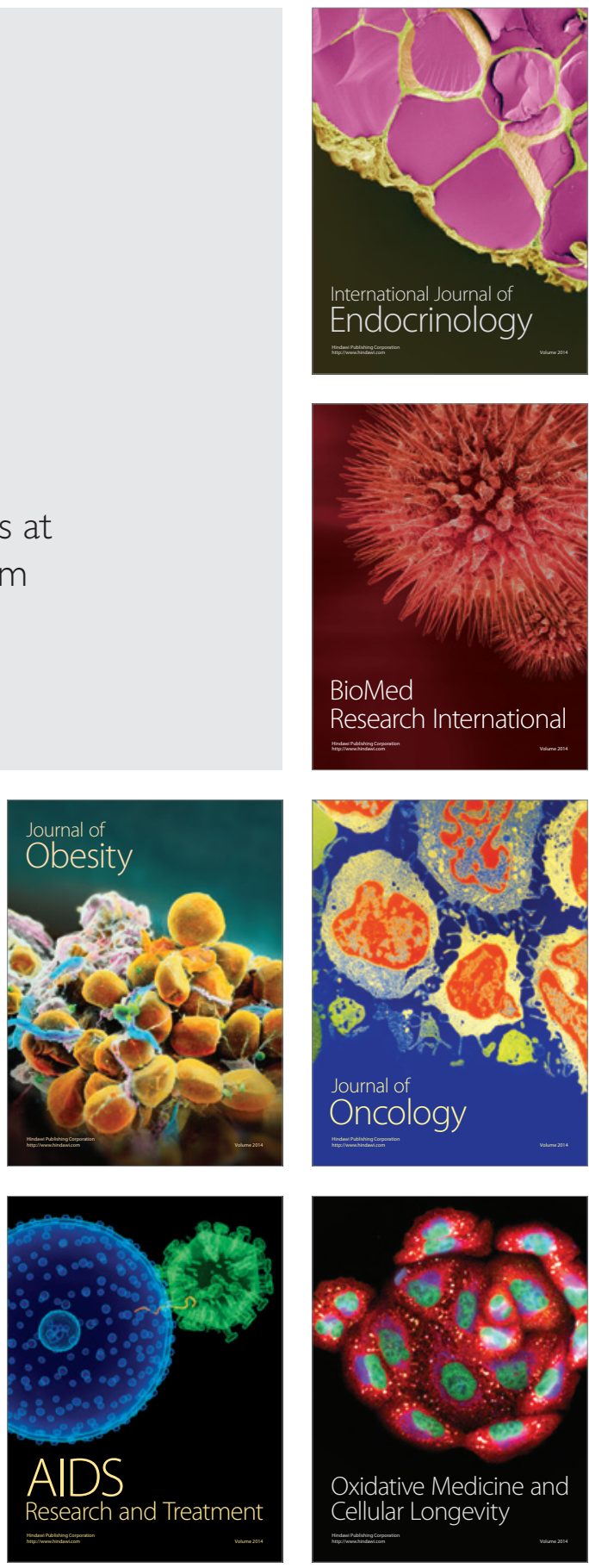